\title{
Chemically-Assigned Classification of Aerosol Mass Spectra
}

\author{
Phillip V. Tan, Oscar Malpica, Greg J. Evans, Sandy Owega, \\ and Michael S. Fila \\ Department of Chemical Engineering, University of Toronto, Toronto, Ontario, Canada
}

\begin{abstract}
An Algorithm for Discriminant Analysis of Mass Spectra-ADAMS-was created that classified aerosol mass spectra into dominant chemically-assigned classes, and grouped rare cases in an outlier class. ADAMS was trained with ambient particulate matter (PM) mass spectra, and then validated through classification tests on known spectra with random noise added, various standard chemicals, and salt-spiked polystyrene latex microspheres. The classification results showed that ADAMS gave a reasonable chemical description of the particle populations. In contrast to adaptive resonance theory (ART-2a) classification, ADAMS could be trained to be advantageously sensitive or insensitive to selected chemical markers. Application of ADAMS to Toronto ambient PM and diesel PM (NIST 2975) demonstrated that these samples could be well described, with a low proportion of the cases falling into the outlier class. Such an algorithm may find application for source-receptor modeling of aerosol mass spectra. (J Am Soc Mass Spectrom 2002, 13, 826-838) @ 2002 American Society for Mass Spectrometry
\end{abstract}

\section{$\mathrm{A}$} recent advancement in aerosol characterization has been the development of techniques to permit on-line, single particle laser ablation mass spectrometry (LAMS). Data acquisition rates of aerosol LAMS instruments are typically of the order of several particles per min [1]. In order to take full advantage of these on-line capabilities, the resulting vast PM dataset requires concurrent summary of the mass spectra for rapid interpretation.

A first approach to reduce large datasets from single aerosols has been to apply pattern recognition programs to the spectra. In work completed by others thus far, a variety of methods including principal components analysis (PCA) [2-5], hierarchical cluster analysis (HCA) [4-6], and adaptive resonance theory (ART$2 \mathrm{a}$-an artificial neural network) [7, 8], were applied. PCA was used to identify highly correlated chemical compounds, but it is inherently a group analysis, making individual particle information like particle size, surface area, or mass difficult to attribute among the principle (chemical) components. Instead of exploring the total variance over the entire population of spectra, both HCA and ART-2a explored the inter-variance between individual spectra and classified similar spectra together. [In HCA and ART-2a, similarities between spectral vectors were measured by a Euclidean distance in HCA, and a Euclidean angle (calculated from the dot

Published online June 11, 2002

Address reprint requests to Dr. G. Evans, Department of Chemical Engineering, University of Toronto, 200 College Street, Toronto, ON M5S 3E5, Canada. E-mail: evansg@chem-eng.utoronto.ca product and commonly expressed as the vigilance factor) in ART-2a. In HCA, spectra with small Euclidean distances between their datavectors are grouped, while in ART-2a, spectra within a threshold vigilance factor are grouped.] An added feature in ART-2a is that it can create new classes when non-original groups are found and do so in an on-line fashion. However there are limitations to these classification approaches for on-line aerosol mass spectra.

One of the limitations of both PCA and HCA is that they are batch processes and thus only appropriate for off-line analysis. Also, HCA and ART-2a group spectra with similar spectral features, but this can be problematic when there is poor spectral reproducibility for a given chemical. In aerosol LAMS the spectral response for standard chemical particles varies significantly in intensity of cluster and fragment ion peaks $[9,10]$. The specific spectrum generated depends on the morphology of the particle, the laser fluence, and the chemical matrix of the particle, instead of only the analyte itself [11]. In HCA and ART-2a, all ion peaks are weighted equally in their similarity analyses and thus, due to the variability in LAMS spectral responses, spectra of similar chemistry may be unnecessarily separated as a result of intense cluster/fragment ions. Furthermore, chemically distinct spectra can be erroneously grouped because of a strong contaminant or impurity peak(s) and ignore minor peak(s) differences that can represent chemical distinction. Although parameters such as the number of clusters in HCA or the vigilance factor in ART-2a can be optimized, they are unsupervised in that there is no training of the programs to either group 
dissimilar spectra into specified chemical classes, or separate spectra based on minor, but chemically significant, spectral components. For aerosol mass spectra classification it is important that chemically similar particles are grouped, not only particles that are spectrally similar.

Another clustering approach has been to apply supervised methods which classify spectra based on predefined groups. Classification and regression trees (CART) [10], discriminant analysis (DA) [3, 6, 12, 13] and supervised fuzzy clustering [14], all of which use predefined chemical groups, have been applied to aerosol mass spectra. The CART and DA methods classified one observation into one predefined chemical group. This is commonly referred to as a "hard" classification where it is assumed that each particle belongs to a single class, and that these classes are mutually exclusive from one another. On the other hand, in the supervised fuzzy c-means algorithm, membership values for a spectrum to each predefined chemical group were derived so that one observation was "soft" classified among one or possibly more chemical classes. In all of these supervised methods a more chemically-based assignment, rather than only spectrally-based classification, was made for each spectrum. However, one difficulty with supervised classification methods is that their accuracy depends in part on the comprehensiveness of the predefined groups. A method that combines the chemical information from supervised training and the versatility of allowing new groups to be accounted for, as in ART-2a, could hence improve the summary of aerosol mass spectra datasets.

Discriminant analysis is a multivariate method that groups data into assigned classes. This approach has been applied to allow unusual cases to be left in an unassigned group [6]. In work completed on scanning electron microscopy energy dispersive X-ray emission spectroscopy of particulate matter, DA was applied to classify particles into chemically-assigned types, and an unassigned type. Applying this supervised classification using DA that allows new classes to be separated could also provide insight for aerosol mass spectra. But DA has only found limited applications in the classification of particle mass spectra. In early off-line laser microprobe mass spectrometry (LAMMS), descriptive DA was tested on Ni standard chemicals, but it was concluded that DA focused on relatively weak ion peaks instead of on the more characteristic strong intensity peaks [3]. In a later study of standard aerosol mixtures of $\mathrm{Cr}$ species, predictive DA that selectively used strong intensity peaks successfully classified the Cr-containing aerosol mass spectra into predefined $\mathrm{Cr}(\mathrm{VI})$ chemical bins [12]. As it stands, a DA that also segregates unassigned cases has not been applied to classification of ambient aerosol mass spectra.

The objective of this work was to develop ADAMS to be used on ambient aerosol mass spectra. ADAMS was developed to classify aerosol mass spectra into chemically-assigned groups, and segregate unassigned classes into an outlier class. The algorithm incorporated

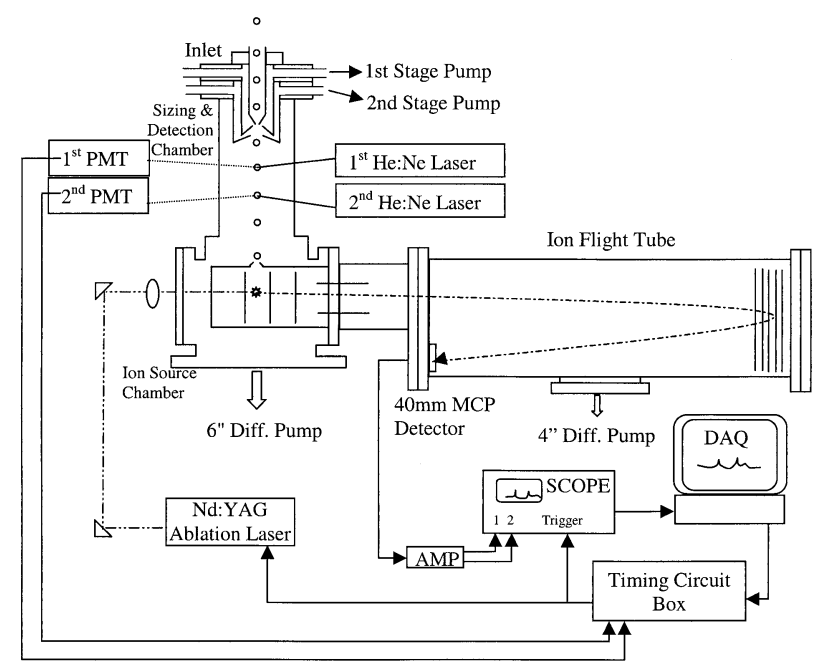

Figure 1. Schematic of the on-line aerosol laser ablation mass spectrometer (LAMS), with two-laser particle sizing.

isotopic ratios and correlations between cluster/fragment ions to dominant ion peaks for determining a criterion for separation of spectra into the outlier class. The ADAMS method was then trained with ambient spectra and validated with spectra from standards. Using this tested algorithm, its ability to provide consistent classification of spectra into major chemical classes and leave rare cases in an outlier class was demonstrated on both ambient and source PM spectra.

\section{Experimental}

\section{Aerosol LAMS Apparatus}

An on-line aerosol laser ablation mass spectrometer was developed at the University of Toronto Aerosol Facility. The design was based on more recent aerosol time-offlight mass spectrometers that have been well described in the literature [15-20].

Our aerosol LAMS (Figure 1) utilized a countersunk 2-stage, $1.5 \mathrm{~L} / \mathrm{min}$ differentially pumped inlet to deliver atmospheric particles into the $\sim 1.3 \times 10^{-6} \mathrm{hPa}$ vacuum of a particle detection chamber and subsequent mass spectrometer. Two $343 \mathrm{~L} / \mathrm{min}$ mechanical pumps provided 5.3 and $0.2 \mathrm{hPa}$ pressures in the first and second stages, respectively, and were used to draw out the majority of the air, leaving a collimated particle beam. Particles that made it through the inlet traveled with a size-dependent terminal velocity. Two orthogonal 10 mW He:Ne laser beams (05LHP991, Melles Griot, Nepean, Ontario, Canada) intersected the particle beam, and photomultiplier tube (PMT) detectors (H5784-01, Hamamatsu Corp., Bridgewater, NJ) were used to detect the occurrence of a particle passing through these He:Ne beams. The He:Ne lasers were spaced $\sim 5 \mathrm{~cm}$ apart where a timing circuit box (Physics Electronics Resource Center, University of Toronto) measured the transit time between a particle passing through the first and then second laser, and allowed the particle's velocity to be 
measured. From this velocity, the timing circuit box appropriately triggered a third laser that ablated/ionized the moving particle when it reached the source region of a reflectron time-of-flight mass spectrometer (AREF, R.M. Jordan Co., Grass Valley, CA). Single particles were ablated/ionized by a $4 \mathrm{~mJ} /(3-5 \mathrm{~ns}$ pulse), $266 \mathrm{~nm}$ Nd:YAG ablation laser (Ultra-CFR, Big Sky Laser, Boseman, MT) focused to $\sim 1.5 \mathrm{~mm}$ in diameter. A positive or negative $4.5 \mathrm{kV} \mathrm{HV}$ power supply (MS1007, K\&M Electronics, West Springfield, MA) was applied to accelerate ions into the drift tube where they were separated in time according to their $\mathrm{m} / \mathrm{z}$. A $40 \mathrm{~mm}$ microchannel plate (MCP) detector with a $300 \mathrm{MHz}$ amplifier (6950, Phillips Scientific, Ramsey, NJ) detected and augmented the spectral signal into a $500 \mathrm{MHz}$ digital storage oscilloscope (DSO, LC334A, LeCroy Corp., Chestnut Ridge, NY). The DSO acquired the raw spectrum after being laser triggered.

\section{PM Sampling}

To analyze Toronto PM in the aerosol LAMS, the PM was first preconcentrated to $10 \times$ its initial number concentration, that ranged from $10-300$ particles $/ \mathrm{cm}^{3}$ for particles $>0.3 \mu \mathrm{m}$. After this concentration, particles were simultaneously sized and chemically analyzed at a typical rate of 1-6 particles/min. Just over 21,000 Toronto particle mass spectra, collected over 10 days in December 2000, were used in this study.

For the analysis of standard chemical samples, a powder disperser (3433 TSI, St. Paul, MN) with a constant output was used to suspend dry material into the aerosol LAMS. Spectra were collected for: manganese powder (MX173, MCB, Norword, $\mathrm{OH}$ ), sodium chloride (S-271B, Fisher, Fairlawn, NJ), cupric sulphate, $\mathrm{CuSO}_{4} \cdot 5 \mathrm{H}_{2} \mathrm{O}$ (C-493, Fisher), aluminum nitrate powder, $\mathrm{AlNO}_{3} \cdot 9 \mathrm{H}_{2} \mathrm{O}$ (ACS 021, BDH, Toronto, Ontario, Canada), graphite powder (28286-3, Aldrich, Milwaukee, $\mathrm{WI})$, and p-toluene sulphonic acid, $\mathrm{CH}_{3}-\mathrm{C}_{6} \mathrm{H}_{4}-$ $\mathrm{SO}_{3} \mathrm{H} \cdot \mathrm{H}_{2} \mathrm{O}$ (A-320, Fisher). Monodisperse, $\sim 2.0 \mu \mathrm{m}$, polystyrene latex (PSL, 19405, Polysciences Inc, Warrington, PA) microspheres were also applied as a test aerosol, and aerosolized using an atomizer system (3940, TSI). The aforementioned sodium chloride and barium nitrate (ACS 126, BDH) at $\sim 0.3 \mathrm{mM} / \mathrm{L}$ were used to spike the PSL.

For the analysis of samples from a PM source, Diesel Particulate Matter (2975, NIST, Gaithersburg, MD) was resuspended using the same setup as for the standard chemicals. Approximately 1000 spectra were collected at each polarity.

\section{Data Acquisition}

Spectra that contained ion peaks greater than $3 \times$ background were transferred through a general purpose interface board (GPIB) to a computer along with their corresponding transit times through a digital input/ output (DIO) board for storage. Each spectrum was simultaneously acquired on two separate scales and combined in software to increase the dynamic range of the spectrum. Prior to saving a spectrum, it was scanned for saturated peaks ( $>2$ Da wide at $>20 \%$ relative intensity) and rejected for storage if saturated peak(s) were found (typically $5-10 \%$ of particles hit by aerosol LAMS were rejected with this screening). National Instruments' LabVIEW 5.1 software (Austin, TX) was used to create a program loop that acquired the transit time and raw spectrum, size and mass calibrated this data for each individual particle, saved this calibrated particle analysis, then rearmed the timing circuit for the next particle. Polarity could also be automatically switched every few seconds using software, and the polarity state of a hit was added to each spectrum file. Additional information appended to each spectrum file included the pulsed laser energy for the particle hit and a timestamp of the analysis.

\section{Calibration}

Particle transit times in the detection chamber were converted to an aerodynamic equivalent diameter (AED) from calibrations that related transit times of monodisperse PSL particles of known size to their AED (where $1.05 \mathrm{~g} / \mathrm{cm}^{3}$ PSL density was used). The particle size range of our instrument was optimized for aerosols with an AED of 0.3 to $3.0 \mu \mathrm{m}$.

Time-scales on raw spectra were initially mass calibrated using ion acceleration equations and the instrument's physical dimensions to calibrate an ion's timeof-flight to $\mathrm{m} / \mathrm{z}$. A duration of $50 \mu \mathrm{s}$ was set for data acquisition (200 M samples/s) to obtain a mass range of nominally $400 \mathrm{Da}$. In this work, calibration accuracy was improved for the aerosol mass spectra studied by manually recalibrating spectra to common chemical peaks. This reduced the uncertainty associated with miscalibrations to $\pm 0.1 \mathrm{Da}$ (up to $\pm 2 \mathrm{Da}$ at $200 \mathrm{Da}$ was observed when constant calibration factors were applied) so that classification accuracy could be more specifically evaluated.

\section{Spectral Analysis}

Each calibrated spectrum was reduced so that an intensity value was derived for every $0.075 \mathrm{Da}$, primarily by omitting data points in the low $\mathrm{m} / \mathrm{z}$ range. With a constant $\mathrm{m} / \mathrm{z}$ separation per data point, a variety of peak search algorithms based on the width of peaks were easily applied across an entire linearized spectrum. The thresholds for accepting chemical peaks were $>7 \sigma_{\mathrm{bkgd}}$ for positive ion mass spectra and $>4 \sigma_{\mathrm{bkgd}}$ for negative ion mass spectra where data points $>300$ Da were used as the background. The lower threshold for negative ion mass spectra was due to the less intense peaks and reduced noise in anion spectra compared to cation spectra.

Four peak search programs were used to find peaks of various mass widths and mass resolutions. One peak search algorithm located peaks with widths between 0.2 and 1.0 Da. Another program fitted a quadratic poly- 
nomial function to every $0.3 \mathrm{Da}$ and determined the maxima of these functions, and their corresponding values. A peak was assigned when peak values exceeded the aforementioned background thresholds. Potential multipeaks with widths $>1.0$ Da were identified through quadratic polynomial fitting on a suspected multi-peak region using widths of 0.225 and $0.525 \mathrm{Da}$, to resolve overlapped peaks. A final program was applied for the identification of very thin peaks. It calculated the average intensity of $0.15 \mathrm{Da}$ regions, and labeled the region a peak if the average intensity exceeded background levels. This last program proved useful for thin peaks represented by only a single intense data point. These programs were run simultaneously for each spectrum and peaks found through multiple methods within $1 \mathrm{Da}$ were combined. The widths and thresholds defined above were found to work well on ambient aerosol mass spectra to detect peaks with a range of peak widths, while minimizing the detection of noise peaks.

Peak areas were determined by applying Simpson's Rule for integration of the identified peak region \pm 0.075 Da. The spectra were individually baseline-corrected using the background so that integrated results represented net areas. The absolute area values (in $\mathrm{V} \cdot \mathrm{Da}$ ) for a peak were normalized by calculating the percentage of the given peak to the total of all peaks in the spectrum. These percentage peak area values were attributed to their corresponding peak centroid rounded to the nearest Da. A spectrum was then represented as a vector with 400 variables where the $n$th variable represented the peak centroid location at $n \mathrm{Da}$, and the value of the variable was the corresponding percentage peak area. This was the format of the spectra for subsequent classification.

\section{Training Set Extraction Using ART-2a and HCA}

The ART-2a classification methodology for aerosol mass spectra has been described in the literature [7]. In this work, ART-2a was applied to 12,790 positive and 8640 negative ambient spectra. LabVIEW 5.1 was used to program the ART-2a algorithm. HCA is a multivariate statistical method for clustering observations and has also been well described in the literature [21]. In this work, HCA was applied to a batch of spectra in each polarity. Minitab 13.30 was used for the HCA and restricted the classification to 5000 spectra. The chemical classes found using ART-2a and HCA identified the initial groups to define in the training set for supervised ADAMS.

\section{ADAMS for Chemically-Assigned Classification}

Our new "algorithm for discriminant analysis for mass spectra-ADAMS" followed six steps. Steps 1, and 4 through 6 are standard for predictive discriminant analysis and are well described in [22-24]. In brief, these steps in DA involve choosing variables that discriminate one group from another, choosing a training set of data with known group affiliations, then deriving a mathematical (classification) function in software for each predefined group to allow new cases to be assessed. Two additional steps to DA are added in ADAMS, steps 2 and 3, that allow outlier spectra to be separated. Detailed descriptions of each of these steps as they relate to aerosol mass spectra, and a simple application to a $\mathrm{Pb}$ class, follows.

In the first step of ADAMS, chemical markers were chosen from each chemical class to discriminate the classes. The markers chosen were usually the base peaks in a chemical class. To fulfill DA requirements, an equal number of markers and chemical groups were chosen. The chemical classes chosen were primarily identified in the PM population by ART-2a and HCA, but were also aided by several recent studies of ambient particles characterized by aerosol LAMS [25-31]. An example of a discriminant chemical marker would be ${ }^{208} \mathrm{~Pb}$ used to characterize a $\mathrm{Pb}$ class.

The second step created an Association Matrix where each discriminant chemical marker was related to all the other spectral peaks. This step was a novel aspect of ADAMS where it departed from conventional DA. In the Association Matrix, weight values were compiled in $j$ rows of non-discriminant chemicals, and $k$ columns of discriminant chemical markers. A weight value between a $k$ th discriminant chemical marker and a $j$ th non-discriminant chemical was simply the ratio of $j: k$ peak areas. Isotopes, fragments, and cluster ions were the usual components that had associations. Natural isotopic abundance tables and relative peak area results from standard chemical mass spectra were used to determine the appropriate weight for these cases. Correlation analysis (Minitab 13.30, State College, PA) between mass peaks was also used to identify associations. When correlations existed but spectra from standards were not available, relative peak area ratios were estimated from ambient spectra. The Association Matrix conceptually is the summary of the "explainable" chemical associations in a spectral dataset. For a Pb class, the marker ${ }^{208} \mathrm{~Pb}$ ion peak would be expected to be associated with its isotopes, and thus a relationship of ${ }^{207} \mathrm{~Pb}=$ $(0.422)^{208} \mathrm{~Pb}$ would be accounted for in the association matrix as would its other isotopes.

The third step in ADAMS calculated the Remainder value, another additional step to DA. The Remainder value applied the Association Matrix to account for all the discriminant chemical markers and their associated peaks, so that what remained was determined. Its calculation was mathematically a sum of all the nondiscriminant chemical peaks in a mass spectrum subtracting any known isotope, fragment, and cluster ion contributions:

$$
R=\sum_{j}\left(\alpha_{j}-\sum_{k} w_{j k} \alpha_{k}\right)\left\{\begin{array}{l}
\text { for all }\left(\alpha_{j}-\sum_{k} w_{j k} \alpha_{k}\right)>0 \\
\text { else } 0
\end{array}\right.
$$


where $R$ is the Remainder value in \% area of a mass spectrum, $\alpha_{j}$ is the \% peak area of a $j$ non-discriminant chemical, $w_{j k}$ is the weight between a $k$ discriminant chemical marker and a $j$ th non-discriminant chemical, and $\alpha_{k}$, the \% peak area of a $k$ th discriminant chemical marker. The formula expresses the difference between the gross ion peak area $\alpha_{j}$ in the spectrum, and the second term that applies weight values from the Association Matrix and can be thought of as an explained (associated) portion of a non-discriminant ion peak. Thus conceptually this Remainder value is the net proportion of the mass spectrum that is unexplained. Continuing the $\mathrm{Pb}$ example, the Remainder quantifies peak area in excess of that accounted for by isotopes (or other known associations). Thus if a given $\mathrm{Pb}$ spectrum contained a $m / z$ peak at $207 \mathrm{Da}$ greater than $(0.422)^{208} \mathrm{~Pb}$, this would be quantified as part of the Remainder. The practical application of ADAMS required several trial iterations before an Association Matrix yielding reasonably small Remainder values was finalized. This Remainder value was calculated for each spectrum classified, and was added to the DA as a new discriminant variable so that spectra with a significant proportion of their peak areas unexplained were marked for an outlier class.

The fourth step of ADAMS established a training set of chemical mass spectra for supervised training of the DA. These spectra were defined by \% peak area values for discriminant chemical markers and the Remainder value. Using a representative training set allowed the typical intensity of the discriminant chemical markers in a chemical class to be determined and thus, indirectly accounted for differences in the relative sensitivity of the markers. For the $\mathrm{Pb}$ class example, training spectra would include particle spectra with dominant ${ }^{208} \mathrm{~Pb}$ ion and allow the possibility of trace contaminants in the spectra such as $\mathrm{Na}$ or $\mathrm{K}$.

The fifth step of ADAMS applied the training set to a conventional DA (Minitab 13.30) to output classification functions (also known as Fischer linear discriminant functions) for each chemical group including the outlier class. The classification function is in the form of a linear combination of variables as follows:

$$
\text { Score }_{i}=a_{i}+b_{i k} \alpha_{k}+\ldots+b_{i R} R
$$

for all $i$ classes over each discriminant variable where $i$ is a chemical class, $a$ is a constant term, and $b$ are the "beta" weights of each discriminant chemical marker's $\%$ peak area, $\alpha_{k}$, and Remainder value, $R$, to an $i$ th class score. In these classification functions, the beta weights of each discriminant chemical marker and the Remainder value to each specific class was obtained. By using training spectra with spectral variability but chemical homogeneity to derive the classification function, discriminant chemical markers would be weighted either in favor, neutral, or in opposition to the designation of a chemical class. A classification function for a Pb class would be weighted in favor of the $\mathrm{Pb}$ variable, and either neutral or negative weights would exist for other discriminant markers due to their irrelevance to the $\mathrm{Pb}$ class.

The sixth and final step predicted the class for unclassified spectra. This was accomplished for each unclassified spectrum by calculating the classification function scores in Eq 2 for each class, and categorizing a spectrum into the chemically-assigned class with the highest score. Because Eq 2 is fixed after training, classification decisions repeatedly yield the same output for a given spectra. This categorizing was not intended to imply that the particle consisted of only the discriminant chemical marker(s), or even that the marker was the predominant component in the particle, but rather that this class was the best description of the particle among the classes defined. Once ADAMS was trained, the Remainder value (step 3) and classification function score calculations (step 6) were the only steps repeated in the algorithm for chemical classification of unclassified data. Thus, to classify a new particle spectrum as $\mathrm{Pb}$, it must have had a classification score for the $\mathrm{Pb}$ class that was higher than any other predefined class or the outlier class.

\section{ADAMS Validation and Application}

Validation of the trained algorithm was tested in three experiments. First, sets of test spectra with added noise were ADAMS classified to determine the robustness of the classification. Second, standard chemicals were analyzed by aerosol LAMS and subsequently classified by ADAMS to identify classification accuracy. Third, characterization of the performance of ADAMS was tested by analysis of PSL particles with different combinations of salts where the advantages of ADAMS over ART-2a classification was illustrated. ADAMS was then applied to both ambient PM and a standard reference material from a PM source to demonstrate the applicability of the technique to different samples.

\section{Results and Discussion}

\section{Toronto PM Chemical Classes for ADAMS Training}

Sized, single particle mass spectra of different chemistry and size ranges were collected from downtown Toronto in the winter of 2000. Classification of these ambient aerosol mass spectra by ART-2a with a vigilance factor of 0.7 (recommended for ambient PM [7]) yielded 24 and 19 major ( $>1 \%$ of the total spectra) classes in the positive and negative ion, respectively. Cumulatively, these classes represented 88 and $72 \%$ of their respective total spectra. HCA with 25 classes also contained major groups that were similar to the ART-2a classification, confirming a reasonable grouping of the spectra. Visual inspection of individual cases in each class showed that low relative intensity ion peaks that could be important 
Table 1. Spectral details of ADAMS chemical classes

\begin{tabular}{|c|c|c|}
\hline & Discriminant chemical markers ${ }^{a}$ & Associated non-markers ${ }^{\text {bc }}$ \\
\hline \multicolumn{3}{|l|}{$(+)$ Chemical class name } \\
\hline $\mathrm{Al}$ & ${ }^{27} \mathrm{Al}$ & ${ }^{70}\left(\mathrm{Al}_{2} \mathrm{O}\right)$ \\
\hline $\mathrm{Ca}$ & ${ }^{40} \mathrm{Ca},{ }^{56}(\mathrm{CaO})$ & ${ }^{57}(\mathrm{CaOH})$ \\
\hline $\mathrm{Fe}$ & ${ }^{56} \mathrm{Fe}$ & \\
\hline K & ${ }^{39} \mathrm{~K}$ & \\
\hline $\mathrm{Mn}$ & ${ }^{55} \mathrm{Mn}$ & ${ }^{71}(\mathrm{MnO})$ \\
\hline $\mathrm{Na}$ & ${ }^{23} \mathrm{Na}$ & \\
\hline $\mathrm{Ti} / \mathrm{C}_{4}$ & ${ }^{48} \mathrm{Ti},{ }^{64}(\mathrm{TiO}),{ }^{48}\left(\mathrm{C}_{4}\right)$ & \\
\hline V & ${ }^{51} \mathrm{~V}$ & ${ }^{67}(\mathrm{VO})$ \\
\hline Metals & Combinations of markers above & \\
\hline $\mathrm{Ba}$ & ${ }^{138} \mathrm{Ba}$ & ${ }^{154}(\mathrm{BaO}),{ }^{155}(\mathrm{BaOH})$ \\
\hline $\mathrm{Mg} / \mathrm{C}_{2}$ & ${ }^{24} \mathrm{Mg},{ }^{24}\left(\mathrm{C}_{2}\right)$ & \\
\hline $\mathrm{NaCl}^{+}$ & ${ }^{81}\left(\mathrm{Na}_{2} \mathrm{Cl}\right),{ }^{23} \mathrm{Na}$ & ${ }^{139}\left((\mathrm{NaCl})_{2} \mathrm{Na}\right),{ }^{46}\left(\mathrm{Na}_{2}\right)$ \\
\hline $\mathrm{NaCl}^{+} /$Metals & $\mathrm{NaCl}^{+}$and Metal markers & \\
\hline $\mathrm{Pb}$ & ${ }^{208} \mathrm{~Pb}$ & \\
\hline $\mathrm{Cu} / \mathrm{Zn}$ & ${ }^{63} \mathrm{Cu},{ }^{64} \mathrm{Zn}$ & ${ }^{79}(\mathrm{CuO}),{ }^{99}(\mathrm{ZnCl})$ \\
\hline Amines/Organics & ${ }^{58}\left(\mathrm{C}_{3} \mathrm{H}_{8} \mathrm{~N}\right),{ }^{30}\left(\mathrm{CH}_{4} \mathrm{~N}\right),{ }^{36}\left(\mathrm{C}_{3}\right)$ & $\begin{array}{l}{ }^{42}\left(\mathrm{C}_{2} \mathrm{H}_{4} \mathrm{~N}\right),{ }^{59}\left(\mathrm{C}_{3} \mathrm{H}_{9} \mathrm{~N}\right),{ }^{70}\left(\mathrm{C}_{4} \mathrm{H}_{8} \mathrm{~N}\right) \\
{ }^{86}\left(\mathrm{C}_{5} \mathrm{H}_{12} \mathrm{~N}\right),{ }^{100}\left(\mathrm{C}_{6} \mathrm{H}_{14} \mathrm{~N}\right)\end{array}$ \\
\hline $\mathrm{C}_{n} \mathrm{H}_{m}^{+} /$Organics & ${ }^{36}\left(\mathrm{C}_{3}\right),{ }^{38}\left(\mathrm{C}_{3} \mathrm{H}_{2}\right),{ }^{48}\left(\mathrm{C}_{4}\right),{ }^{61}\left(\mathrm{C}_{5} \mathrm{H}\right),{ }^{24}\left(\mathrm{C}_{2}\right)$ & $\mathrm{C}_{n} \mathrm{H}_{m}$ for $\mathrm{n}=1$ to $10 ; \mathrm{m}=0$ to 3 \\
\hline K/Organics & $\begin{array}{l}\mathrm{K} \text { and } \mathrm{Amines} / \text { Organic markers } \\
\mathrm{K} \text { and } \mathrm{C}_{n} \mathrm{H}_{m} / \text { Organic markers }\end{array}$ & \\
\hline $\mathrm{NO} / \mathrm{CH}_{4} \mathrm{~N} /$ Organics & ${ }^{30}(\mathrm{NO}) /{ }^{30}\left(\mathrm{CH}_{4} \mathrm{~N}\right)$ & $\begin{array}{l}{ }^{59}\left(\mathrm{C}_{3} \mathrm{H}_{9} \mathrm{~N}\right),{ }^{70}\left(\mathrm{C}_{4} \mathrm{H}_{8} \mathrm{~N}\right),{ }^{86}\left(\mathrm{C}_{5} \mathrm{H}_{12} \mathrm{~N}\right), \\
\mathrm{C}_{n} \mathrm{H}_{m} \text { for } n=1 \text { to } 6 ; m=0 \text { to } 2,\end{array}$ \\
\hline $\begin{array}{l}\text { Outlier }^{+} \text {class } \\
(-) \text { Chemical class name }\end{array}$ & Remainder discriminant variable & \\
\hline $\begin{array}{l}\text { Sulphates } \\
\text { Suass name }\end{array}$ & ${ }^{97} \mathrm{HSO}_{4}$ & ${ }^{16} \mathrm{O},{ }^{17}(\mathrm{OH}){ }^{195}\left(\mathrm{H}_{3}\left(\mathrm{SO}_{4}\right)_{2}\right)$ \\
\hline Nitrates & ${ }^{46}\left(\mathrm{NO}_{2}\right),{ }^{62}\left(\mathrm{NO}_{3}\right)$ & ${ }^{16} \mathrm{O},{ }^{17}(\mathrm{OH}),{ }^{125}\left(\mathrm{H}\left(\mathrm{NO}_{3}\right)_{2}\right)$ \\
\hline Sulphates/Nitrates & Sulphate and Nitrate markers & \\
\hline $\mathrm{H} / \mathrm{C}_{2} /$ Organics & ${ }_{72}^{1} \mathrm{H},{ }^{24}\left(\mathrm{C}_{2}\right),{ }^{19} \mathrm{~F}$ & ${ }^{25} \mathrm{C}_{2} \mathrm{H},{ }^{26}(\mathrm{CN}) /{ }^{26}\left(\mathrm{C}_{2} \mathrm{H}_{2}\right),{ }^{16} \mathrm{O},{ }^{17}(\mathrm{OH})$ \\
\hline $\mathrm{C}_{n} \mathrm{H}_{m}^{-}$ & ${ }^{72}\left(C_{6}\right),{ }^{24}\left(C_{2}\right)$ & $\mathrm{C}_{n} \mathrm{H}_{m}$ for $n=1$ to $10 ; m=0$ to 3 \\
\hline Sulphate/Organics & $\begin{array}{l}\text { Sulphate and } \mathrm{H} / \mathrm{C}_{2} / \text { Organic markers } \\
\text { Sulphate and } \mathrm{C}_{n} \mathrm{H}_{m} \text { markers }\end{array}$ & \\
\hline Sulphates/Nitrates/Organics & $\begin{array}{l}\text { Sulphate, nitrate and } \mathrm{H} / \mathrm{C}_{2} / \text { Organic markers } \\
\text { Sulphate, nitrate and } \mathrm{C}_{2} \mathrm{H}_{m} \text { markers }\end{array}$ & \\
\hline $\mathrm{Cl} /$ Organics & $\begin{array}{l}{ }^{35} \mathrm{Cl} \text { and } \mathrm{H} / \mathrm{C}_{2} / \text { Organic markers } \\
{ }^{35} \mathrm{Cl} \text { and } \mathrm{C}_{n} \mathrm{H}_{m} \text { markers }\end{array}$ & \\
\hline Silicates/Organics & $\begin{array}{l}{ }^{76}\left(\mathrm{SiO}_{3}\right),{ }^{59}\left(\mathrm{C}_{3} \mathrm{H}_{7} \mathrm{O}\right) \text { and } \mathrm{H} / \mathrm{C}_{2} / \text { Organic markers } \\
{ }^{76}\left(\mathrm{SiO}_{3}\right),{ }^{59}\left(\mathrm{C}_{3} \mathrm{H}_{7} \mathrm{O}\right) \text { and } \mathrm{C}_{n} \mathrm{H}_{m} \text { markers }\end{array}$ & ${ }^{60}\left(\mathrm{SiO}_{2}\right)$ \\
\hline Silicates/Nitrates & Silicate and nitrate markers & \\
\hline $\mathrm{NaCl}^{-}$ & ${ }^{93}\left(\mathrm{NaCl}_{2}\right),{ }^{35} \mathrm{Cl}$ & ${ }^{151}\left((\mathrm{NaCl})_{2} \mathrm{Cl}\right)$ \\
\hline Outlier $^{-}$class & Remainder discriminant variable & \\
\hline
\end{tabular}

aDiscriminant chemical markers indicate ion markers used to segregate the defined classes.

${ }^{b}$ Associated non-markers indicate cluster or fragment ion peaks commonly found with a marker.

${ }^{\mathrm{c} N o t}$ including isotopes and isotopic compounds.

to interpretation were randomly present in the individual spectra, but the major ion peaks were of similar response to class averages. When classes were made more spectrally homogenous even for minor ion peaks by using a vigilance factor $>0.7$ in ART-2a, or equivalently in HCA by specifying a higher number of clusters, this resulted in many classes of only subtle differences and complicated interpretation. When a vigilance factor $<0.7$ (recommended for standard chemicals [8]) or a decreased number of cluster groups was chosen, spectra classified together were not always chemically similar. These observations indicated that a fixed vigilance factor or number of groups each had drawbacks for interpretation purposes, but the initial 0.7 and 25 values, respectively, were adequate for initially identifying the major chemical groups in the ambient dataset.

The ART-2a and HCA classes found in the spectra were then used to derive 12 and 8 chemically-assigned ADAMS classes, for positive and negative, respectively. The number of ART-2a classes was iteratively reduced by combining similar classes and removing minor ones, while ensuring that the proportion of spectra in the outlier class was $<10 \%$. A supplemental 7 positive and 3 negative classes were added to ADAMS for environmental and PM source tracing interests, although they were not major ART-2a or HCA classes. Table 1 defines the chemical classes used in ADAMS. The first column of the table gives the chemical class names, while the 
second column indicates the marker ion peak that was used for a given class. The names were chosen in an effort to give the best description of the mass spectrum, segregate it from equivalent classes in different polarities (e.g., $\mathrm{NaCl}^{+}$versus $\mathrm{NaCl}^{-}$), and also minimize confusion between the chemical class and the primary marker used to identify it (e.g., Sulphates was used to describe a bisulphate $\left[\mathrm{HSO}_{4}^{-}\right]$spectrum). To facilitate distinction between specific chemical classes and other chemical references (such as markers or groups of classes), ADAMS chemical classes are capitalized when referred to in the text that follows. For future applications of ADAMS, the class names and their chemical interpretation will be used interchangeably.

In addition to chemical classes described by one component, ADAMS classes included mixtures that were prevalent such as Metals, or $\mathrm{NaCl}^{+} /$Metals, or Nitrates/Sulphates, so that various combinations of the peaks in such mixes did not each require a predefined chemical class. Selection of representative classes, including mixtures of classes, was important because spectra with almost equal classification scores for multiple classes would otherwise be assigned to only a single class. The classes containing organics were not further subdivided beyond their marker(s). This was due to the variability and complexity of organic ion peaks from aerosol mass spectra. Work on identifying organic tracers from standards should improve organic segregation and interpretation in future ADAMS classifications [32, 33].

The set of discriminant chemical markers chosen (Table 1) were base peaks in spectra, or for the supplemental non-major classes, these were the chemical ion of interest. Although markers could have multiple chemical identities, for example ${ }^{56}(\mathrm{CaO})$ and ${ }^{56} \mathrm{Fe}$, classes that applied to such markers were not necessarily collinear as discrimination was based on the intensity of all the markers in the spectrum, not just presence or absence of any single peak. The more stringent presence or absence criteria, in our experience, overweighed possible noise and minor peaks. In two minor classes, ${ }^{48} \mathrm{Ti} /{ }^{48}\left(\mathrm{C}_{4}\right)$ and ${ }^{24} \mathrm{Mg} /{ }^{24}\left(\mathrm{C}_{2}\right)$, which were deemed possibly important for PM source tracing, class designation was mixed to leave an indication of the possible chemistry, while still flagging that the identification required confirmation. Associated non-markers listed in Table 1 were the main chemical constituents that were weighted in the Association Matrix for ADAMS. These associated non-markers (and isotopes which were not listed due to space) were ion peaks that essentially added variability to the spectra, without adding chemical information.

ADAMS was trained with $>20$ individual ambient spectra chosen from each chemical class assigned in Table 1 . The training set was selected to represent the spectral variability within each chemical class and hence, derived robust classification functions for the chemical classes. From the choice of the training set, classification functions were derived to be sensitive or insensitive to specific markers.

\section{ADAMS Validation}

Spectra with random noise. To characterize the performance of ADAMS after training, the algorithm first classified mass spectra of known spectral identity. This validation test applied ADAMS to test sets of spectra that were derived from the training spectra with random variability of up to $\pm 50 \%$ applied to their peak intensities. For 100 test spectra in each predefined chemical classes, tested with five separate trials, ADAMS correctly classified the test set an average of $97.0 \pm$ $0.1 \%$ of the time (Figure 2a). The few misclassifications were primarily in logical neighbors where $\mathrm{NaCl}^{+}$/ Metals spectra were sometimes misclassified into the pure $\mathrm{NaCl}^{+}$class, or spectra from the Metals class with a major metal component were sometimes classified instead into a dominant metal class. Further inspection of the apparent misclassifications revealed that the random variability added could transform a spectrum from its original group to legitimately belong to another. Thus, the percentage of true misclassifications by ADAMS was further reduced. Similar accuracy was found for the test in the negative ion where classes were correctly grouped $96.4 \pm 0.1 \%$ on average (Figure $2 b$ ). Misclassifications of anion spectra were primarily between organic groups. For the outlier classes which consisted of random peaks, good segregation of these spectra was found. The results demonstrate the high accuracy and precision of ADAMS to classify spectra with varying ion intensities, as is expected from aerosol LAMS.

Standard chemical spectra. A test of the chemical accuracy of the ADAMS classification was completed by running the method on spectra collected from standard chemicals. An example of a characteristic spectrum from each selected chemical is shown in Figure 3. Manganese metal mass spectra were relatively pure with intense $\mathrm{Mn}^{+}$and the occasional $\mathrm{K}^{+}$or alkali metal contaminant (Figure 3a). Spectra from sodium chloride (Figure $3 \mathrm{~b}$ ) contained $\mathrm{Na}_{x} \mathrm{Cl}_{x-1}^{+}$for $x=1$ to 3 where peak intensities usually decreased as $x$ increased, and sometimes also the Na dimer ion was detected. For cupric sulphate (Figure 3c) a strong $\mathrm{Cu}$ cation with both its isotopes and the $\mathrm{Cu}$ dimer were usually seen, while various hydrated and oxide forms of $\mathrm{Cu}$ were random. Aluminum nitrate particle spectra (Figure 3d) typically showed $\mathrm{Al}^{+}, \mathrm{NO}^{+}$, and $\mathrm{NO}_{2}^{+}$ion peaks, with often the $\mathrm{NO}_{2}^{+}$ion peak also present as monohydrate and up to dihydrate. Small carbon contaminants from $\mathrm{C}_{1}^{+}$and $\mathrm{C}_{4}^{+}$ were also detected in this particular spectrum of aluminum nitrate. In graphite spectra (Figure 3e), carbon clusters, $\mathrm{C}_{n}{ }^{+}$, of $n=7$ to 11 were usually seen, with random minor impurities such as $\mathrm{Ca}^{+}$. Finally, ptoluene sulphonic acid spectra were quite variable. Two distinct spectra are shown in Figure $3 \mathrm{f}-\mathrm{i}$ and Figure 


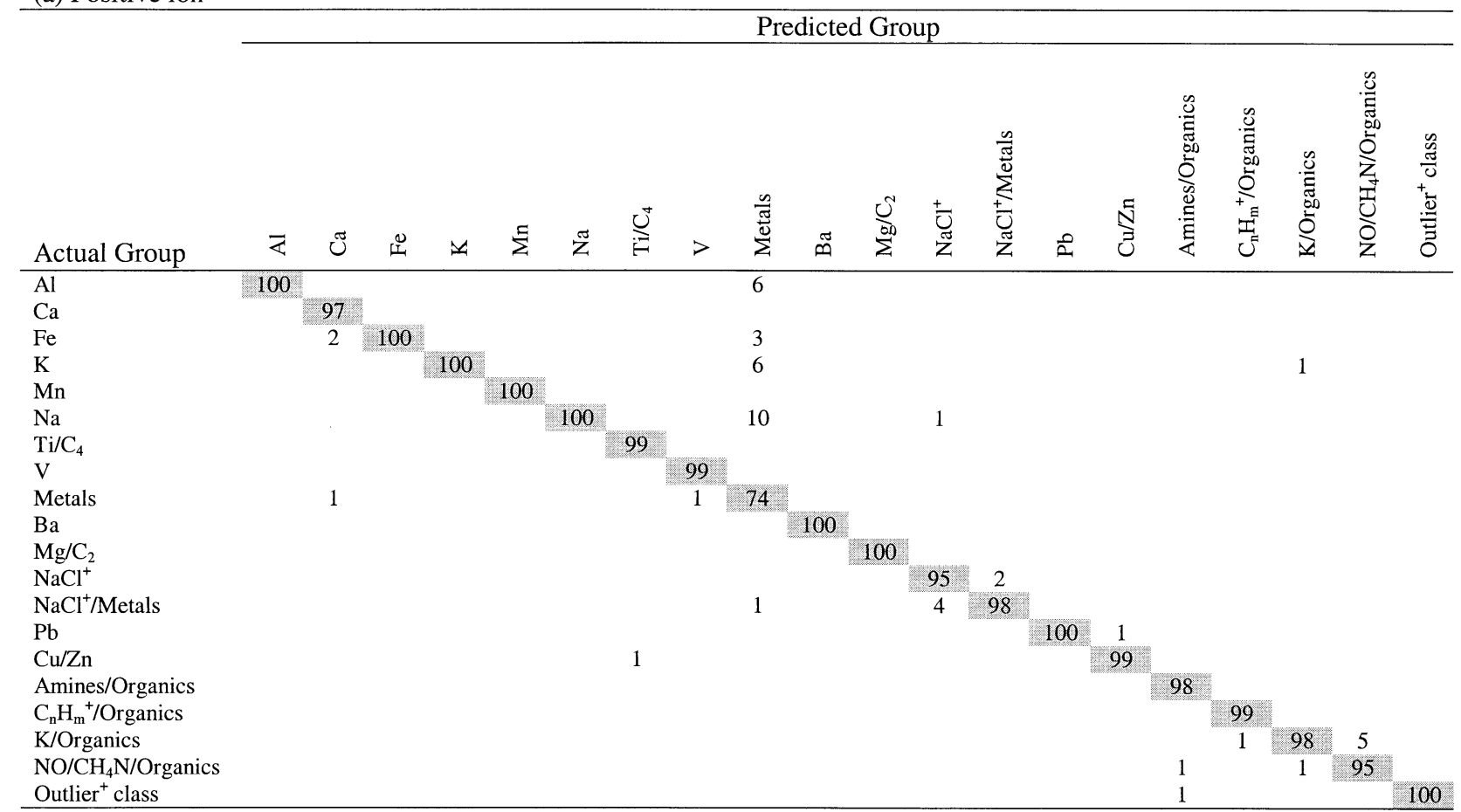

\begin{tabular}{|c|c|c|c|c|c|c|c|c|c|c|c|c|}
\hline \multirow[b]{2}{*}{ Actual Group } & \multicolumn{12}{|c|}{ Predicted Group } \\
\hline & Sulphates & Nitrates & $\begin{array}{l}\text { Sulphates } \\
\text { /Nitrates }\end{array}$ & $\mathrm{H} / \mathrm{C}_{2} / \mathrm{Org}$ & $\mathrm{C}_{\mathrm{n}} \mathrm{H}_{\mathrm{m}} \cdot$ & $\begin{array}{c}\text { Sulphate/ } \\
\text { Org }\end{array}$ & $\begin{array}{c}\text { Sulphates } \\
\text { /Nitrates/ } \\
\text { Org } \\
\end{array}$ & $\mathrm{Cl} / \mathrm{Org}$ & $\begin{array}{c}\text { Silicates/ } \\
\text { Org }\end{array}$ & $\begin{array}{c}\text { Silicates/ } \\
\text { Nitrates }\end{array}$ & $\mathrm{NaCl}^{-}$ & Outlier \\
\hline Sulphates & 100 & & 4 & & & & & & & & & \\
\hline Nitrates & & 100 & 6 & & & & & & & & & \\
\hline Sulphates/Nitrates & & & 89 & & & & & & & & & \\
\hline $\mathrm{H} / \mathrm{C}_{2} / \mathrm{Org}$ & & & & 95 & & & & & & & & \\
\hline $\mathrm{C}_{\mathrm{n}} \mathrm{H}_{\mathrm{m}}$ & & & & & 95 & & & & & & & \\
\hline Sulphate/Org & & & & & & 99 & 7 & 1 & & & & \\
\hline Sulphates/Nitrates/Org & & & & & 3 & 1 & 83 & & & & & \\
\hline $\mathrm{Cl} / \mathrm{Org}$ & & & & 2 & 2 & & 10 & 99 & 1 & & 1 & \\
\hline Silicates/Org & & & & 2 & & & & & 99 & & & \\
\hline Silicates/Nitrates & & & 1 & & & & & & & 100 & & \\
\hline $\mathrm{NaCl}^{-}$ & & & & 1 & & & & & & & 99 & \\
\hline Outlier & & & & & & & & & & & & 100 \\
\hline
\end{tabular}

Figure 2. ADAMS classification of test spectra with noise deliberately added. (a) Positive ion mode spectra, (b) negative ion mode spectra.

$3 \mathrm{f}-\mathrm{ii}$, where lower and higher hydrocarbon clusters, respectively, were produced by this organic compound.

A total of 40 spectra from each chemical were used in this classification test. ADAMS classification results are shown in Figure 4. The chemical groupings showed that manganese, sodium chloride, and cupric sulphate were categorized within their own related classes, while being well separated from other classes. For sodium chloride and cupric sulphate which both shared common 81 and 83 Da peaks, for $\mathrm{Na}_{2} \mathrm{Cl}^{+}$(Figure $3 \mathrm{~b}$ ) and $\mathrm{Cu} \cdot \mathrm{H}_{2} \mathrm{O}^{+}$(Figure $3 \mathrm{c}$ ), respectively, there were no misclassifications of these spectra. The results reinforced that the classification was not based on the simple presence or absence of a discriminant chemical marker. In the case of alumi- num nitrate, ADAMS was not trained with this class, however, the spectra were understandably described by ADAMS as a mixture of Al class particles and $\mathrm{NO}$ class particles. Carbonaceous graphite and p-toluene sulphonic acid (TSA) were grouped together in hydrocarbon and organic-related ADAMS classes with a significant fraction of the TSA falling into the outlier ${ }^{+}$ class. Some Ca contaminant spectra were also present in these standard chemicals. Calcium related particles were found in the aluminum nitrate and graphite samples, and some of the aluminum nitrate contained strong carbonaceous impurity. Generally though, the classification results showed that ADAMS obtained a reasonable chemical description of the particle population. 


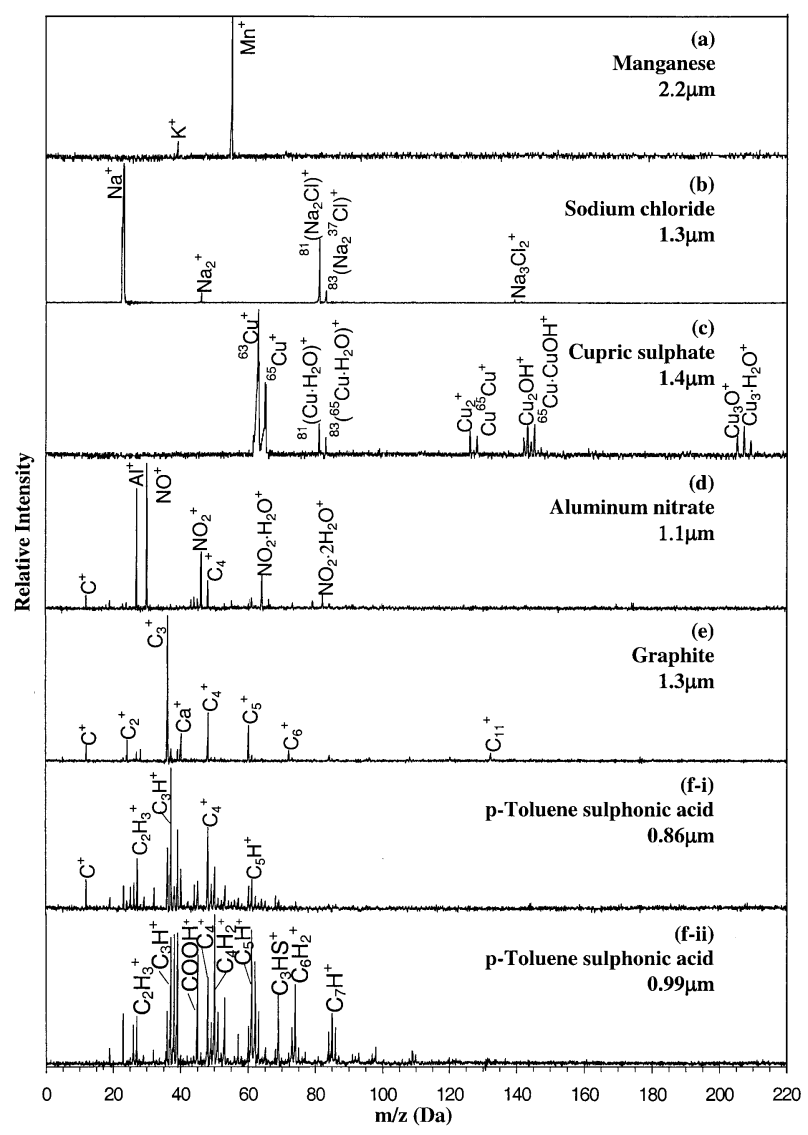

Figure 3. Single particle mass spectra in the positive ion mode for selected standard chemicals: (a) Manganese, (b) sodium chloride, (c) cupric sulphate, (d) aluminum nitrate, (e) graphite, and (f) p-toluene sulphonic acid.

Polystyrene latex (PSL) particle spectra. The ADAMS method was tested with plain PSL spectra and PSL spiked with different salts to demonstrate the advantages of the trained method over ART-2a. Spectra shown in Figure 5 describe the PSL under these various conditions. Plain PSL displayed characteristically intense $\mathrm{C}_{n} \mathrm{H}^{+}$peaks for odd $n=3,5,7,9$, and strong

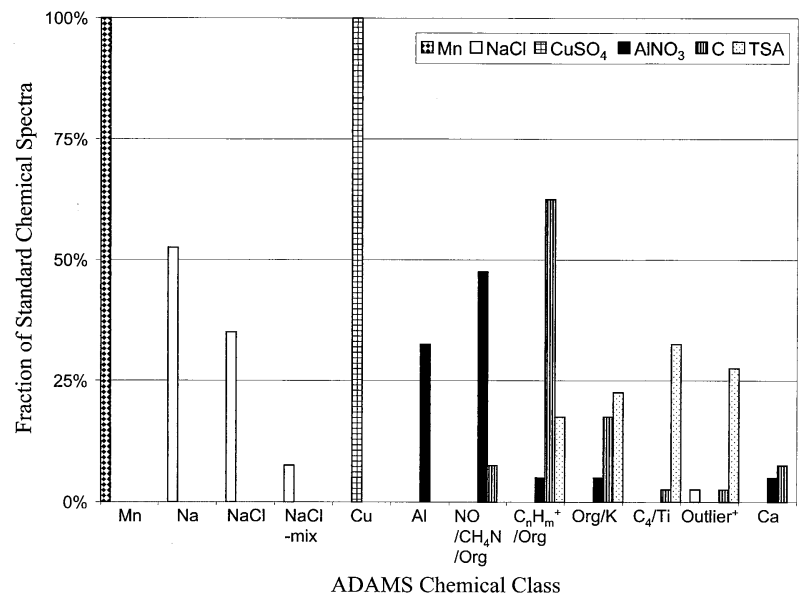

Figure 4. ADAMS classification of selected standard chemicals.

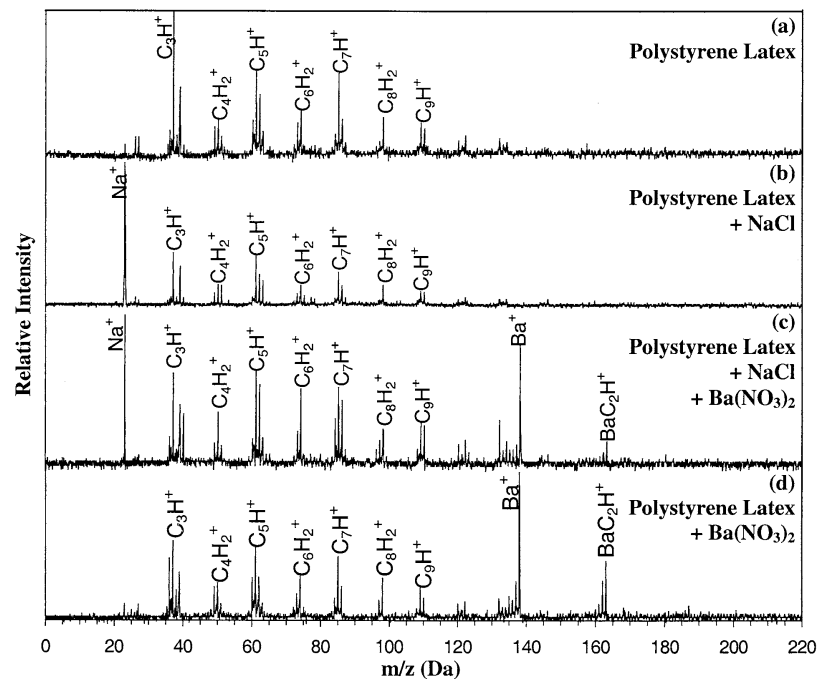

Figure 5. Single particle mass spectra in the positive ion mode for $2 \mu \mathrm{m}$ polystyrene latex (PSL) particles with (a) no salt added, (b) $\mathrm{NaCl}$, (c) $\mathrm{NaCl}$ and $\mathrm{Ba}\left(\mathrm{NO}_{3}\right)_{2}$, and (d) $\mathrm{Ba}\left(\mathrm{NO}_{3}\right)_{2}$.

$\mathrm{C}_{n} \mathrm{H}_{2}^{+}$for even $n=4,6,8$ (Figure 5a). When sodium chloride was added to the PSL, the $\mathrm{Na}^{+}$ion peak was detected (Figure $5 \mathrm{~b}$ ) with the plain PSL signature. Ion peaks at ${ }^{138} \mathrm{Ba}^{+}$and ${ }^{163}\left(\mathrm{BaC}_{2} \mathrm{H}\right)^{+}$were detected in the spectra obtained by adding barium nitrate to PSL (Figure 5d). Both Na and Ba peaks were present for PSL spiked with barium nitrate and sodium chloride (Figure 5c). A total of 40 spectra were collected for each condition, and used in this classification test.

A comparison of the classification results for ADAMS and ART-2a on the PSL samples is shown in Figure 6. In ADAMS, mass spectra were classified according to its training where most spectra containing Ba were grouped together, and those without Ba were grouped into a hydrocarbon-related class. ADAMS did not simply measure the presence or absence of $\mathrm{Ba}$, but was trained on the "typical" amount of Ba expected to be present in a Ba particle. Thus, particles which showed an extremely low Ba intensity were classified into the hydrocarbon class. In contrast, ART-2a grouped spectra based on spectral similarity: Class 2 was spectra with hydrocarbons and an intense Ba peak, class 1 was mainly hydrocarbons, and class 3 was hydrocarbons and a strong Na. What is evident from the two plots is that ART-2a generally grouped all the various PSL mixtures together into one class of initially unnamed identity, whereas ADAMS separated Ba-containing spectra from those that were hydrocarbon in nature.

One of the advantages of ADAMS over unsupervised ART-2a was that there was no need to go back and associate chemicals of interest to classes, as is required for ART-2a, because ADAMS inherently combines particles into classes of chemical interest. Another advantage was that ADAMS was intentionally insensitive to components like $\mathrm{Na}^{+}$, which is often an impurity or contaminant that doesn't usually add much information to the chemistry or origin of the particle. Concur- 

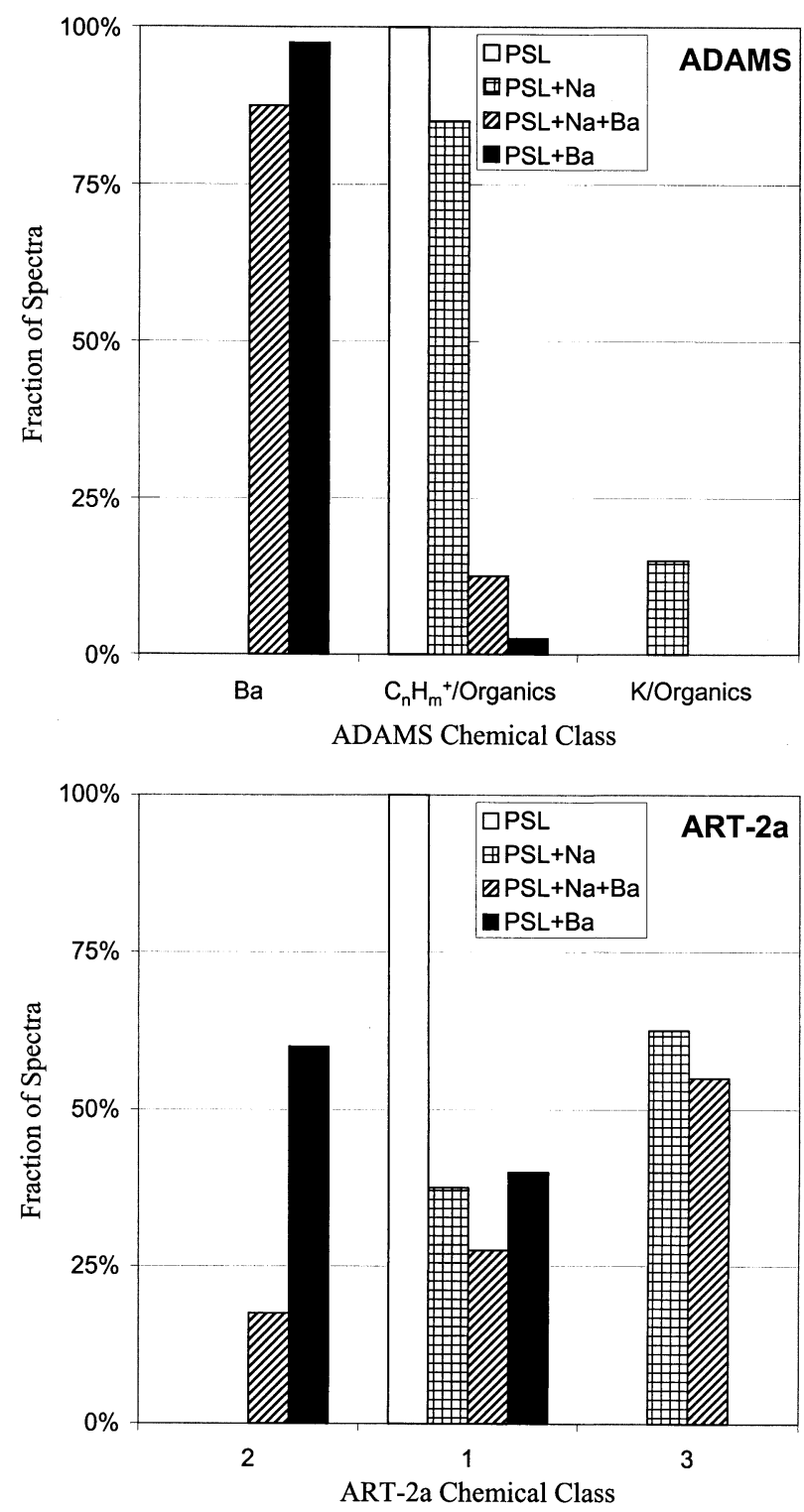

Figure 6. ADAMS versus ART-2a classification of PSL particles with different salt additions.

rently, ADAMS was preferentially sensitive to the $\mathrm{Ba}$ discriminant chemical marker which is a chemical of environmental interest. This ability is beneficial in complicated spectra where only one or few chemicals are of interest, and the subtle spectral differences are difficult to distinguish using ART-2a. Such sensitivity is evident from the ADAMS detection of PSL that contained $\mathrm{K}^{+}$. In this case the spectra contained $\mathrm{K}^{+}$because of contamination from the $\mathrm{NaCl}$, however, in ambient particles, $\mathrm{K} /$ Organics can be an indicator for combustion sources and thus ADAMS was trained to be sensitive to $\mathrm{K}$ among organic peaks. The validation tests performed on ADAMS for standard chemicals and PSL particles demonstrated the versatility of ADAMS when applied to different types of samples with no new training.
Table 2. Distribution of chemical classes in Toronto PM and a diesel PM source (NIST 2975) by ADAMS classification ${ }^{\text {a }}$

\begin{tabular}{|c|c|c|}
\hline & $\begin{array}{c}\text { Toronto } \\
\text { PM }^{\mathrm{a}}\end{array}$ & $\begin{array}{r}\text { Diese } \\
\text { PM }^{\text {a }}\end{array}$ \\
\hline \multicolumn{3}{|l|}{ (+) Chemical class } \\
\hline Al & 3.1 & 0.8 \\
\hline $\mathrm{Ca}$ & 2.8 & 2.1 \\
\hline $\mathrm{Fe}$ & 3.0 & 0.2 \\
\hline $\mathrm{K}$ & 19.5 & 0.5 \\
\hline $\mathrm{Mn}$ & 0.5 & \\
\hline $\mathrm{Na}$ & 8.0 & 0.3 \\
\hline $\mathrm{Ti} / \mathrm{C}_{4}$ & 0.6 & 0.2 \\
\hline$V^{-4}$ & 1.0 & \\
\hline Metals & 7.8 & 1.2 \\
\hline $\mathrm{Ba}$ & 0.4 & 0.0 \\
\hline $\mathrm{Mg} / \mathrm{C}_{2}$ & 0.5 & 1.9 \\
\hline $\mathrm{NaCl}^{+}$ & 1.5 & \\
\hline $\mathrm{NaCl}^{+} /$Metals & 1.0 & 0.1 \\
\hline $\mathrm{Pb}$ & 1.1 & \\
\hline $\mathrm{Cu} / \mathrm{Zn}$ & 1.0 & \\
\hline Amines/Organics & 14.4 & \\
\hline $\mathrm{C}_{n} \mathrm{H}_{m}{ }^{+} /$Organics & 3.0 & 78.0 \\
\hline K/Organics & 11.6 & 2.2 \\
\hline $\mathrm{NO} / \mathrm{CH}_{4} \mathrm{~N} /$ Organics & 12.3 & 8.6 \\
\hline Outlier $^{+}$class & 6.6 & 3.9 \\
\hline \multicolumn{3}{|l|}{ (-) Chemical class } \\
\hline Sulphates & 29.6 & \\
\hline Nitrates & 29.4 & 0.1 \\
\hline Sulphates/Nitrates & 15.1 & \\
\hline $\mathrm{H} / \mathrm{C}_{2} /$ Organics & 7.0 & 30.5 \\
\hline $\mathrm{C}_{n} \mathrm{H}_{m}-$ & 1.2 & 67.1 \\
\hline Sulphate/Organics & 5.7 & 0.6 \\
\hline Sulphates/Nitrates/Organics & 4.3 & 0.1 \\
\hline $\mathrm{Cl} /$ Organics & 2.1 & 1.0 \\
\hline Silicates/Organics & 0.3 & \\
\hline Silicates/Nitrates & 0.8 & 0.1 \\
\hline $\mathrm{NaCl}^{-}$ & 0.8 & \\
\hline Outlier ${ }^{-}$class & 3.8 & 0.5 \\
\hline $\begin{array}{l}\text { Number of }(+) \text { spectra } \\
\text { collected }\end{array}$ & 12,790 & 1,070 \\
\hline $\begin{array}{l}\text { Number of (-) spectra } \\
\text { collected }\end{array}$ & 8,640 & 935 \\
\hline
\end{tabular}

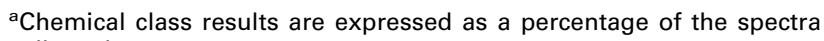
collected.

\section{ADAMS Application to Ambient PM}

With ADAMS trained and validated, it was applied to the complete 10-day sampling campaign of ambient aerosol LAMS mass spectra. Classification results showed the proportions of chemical groups in the spectra from Toronto PM (Table 2). The majority of the Toronto PM analyzed were K and/or organic-related in the cation spectra, while the abundant anion spectra were classified as sulphate and/or nitrate. As expected from the method for choosing chemical classes, the outlier classes for both polarities was $<7 \%$, but this was far better than the $28 \%$ (positive) and $12 \%$ (negative) of minor classes that were ignored by ART-2a. The somewhat coarse chemical groupings in ADAMS effectively allowed more spectra from minor groups to be classified, as many of them only differed by recognizable fragment or cluster peaks. Manual inspection of the 
spectra in each group, including groups with small proportions, identified that most ADAMS classifications were chemically accurate.

The ADAMS outlier classes contained some ambient spectra that could have been chemically classified. These outlier spectra consisted mainly of organic spectra without any marker peaks, metal $+\mathrm{H}$ spectra, and miscalibrated spectra. The outlier classes revealed that classification was sensitive to calibration and peak search accuracy; but only a small number of particles were classified into the outlier classes and indicated, in by far the majority of the particles, that most of the peaks could be explained. In fact less than $25 \%$ of the spectral area was unexplained in the spectra of over $80 \%$ of the ambient particles, and for the negative ion spectra which had fewer spurious peaks, less than $20 \%$ of the spectral area was unexplained for almost $90 \%$ of the particles. The low Remainder values for most spectra indicated that the chemical correlations in the Association Matrix were fairly complete for the dataset analyzed. The Remainder value will be monitored in future work to diagnose our "knowledge" of the mass spectral associations that exist, and may help in directing which mass spectral components require further mass spectrometry understanding.

Interpretation of these classification results back to their actual ambient levels requires a better understanding of the relationship between sensitivity and particle detection efficiency. Some work has been done on relative sensitivity factors (RSFs) [34] of individual peaks within a spectrum and on particle size detection efficiency [35], but not on a chemical class basis. If a comprehensive set of chemical classes can be agreed upon, then limiting the RSF evaluations to these chosen classes can minimize the necessary investigations. Although inter-chemical class comparisons may require class RSFs, temporal trends within a class may be used to indicate fluctuations in that chemical's relative level, provided corrections for size biases are incorporated, and assuming that these size biases are compositionally independent.

\section{ADAMS Application to a PM Source}

The same trained ADAMS was applied to classify spectra from diesel PM. ADAMS classification (Table 2) identified that the major proportion of particles in diesel PM were carbonaceous and belonged to the $\mathrm{C}_{n} \mathrm{H}_{m}{ }^{+}$/ Organics and $\mathrm{C}_{n} \mathrm{H}_{m}{ }^{-}$classes. The grouping of PM from a mobile source into primarily carbonaceous and organic groups was also found in other aerosol mass spectra of vehicle exhausts [28, 36-38]. Smaller contributions from $\mathrm{Ca}$, $\mathrm{K} /$ Organic, and $\mathrm{NO} / \mathrm{CH}_{4} \mathrm{~N} / \mathrm{Org}$ were found in the positive ion, while $\mathrm{H} / \mathrm{C}_{2} /$ Organics, and $\mathrm{Cl} /$ Organics were identified in the negative. These smaller class contributions were expected as well, because work completed earlier on PM sources found that particle types from a standard PM source were chemi- cally diverse [38]. The outlier classes were also small with $<3.9 \%$ of the spectra in these classes. These results showed that the same ADAMS scheme trained and applied to ambient could provide a consistent classification for a PM source. This consistency is important because it has been noted that a classification method for both source and ambient is a necessity for apportioning ambient aerosol LAMS data back to its original source(s) (receptor modeling) [38].

In recent work that studied that application of classification to source apportionment and receptor modeling accuracy, it was identified that there is a need for tracer-based classification of particles [39] rather than only classification of spectra with similar ion signals. In future ADAMS classification algorithms, the use of source tracers instead of base peaks could be selected for the discriminant markers, creating a discriminant "source" marker. Analogously, instead of chemicallyassigned classification of aerosol mass spectra, future application of the algorithm will be a PM source-assigned classification. Such ADAMS applications to source apportionment studies will, however, require extensive investigations of PM sources to ensure marker uniqueness.

\section{Potential of ADAMS}

The ADAMS method has shown its utility in its ability to give consistent, easily interpretable results from mass spectra of standard chemicals, ambient PM, and PM from diesel emissions. Although these results are encouraging, more PM sources and ambient PM samples over various seasons and locations need to be studied so that the comprehensiveness of ADAMS classes for PM characterization can be assessed. The combination of both an exploratory method such as ART-2a and ADAMS could be used to facilitate investigation of any significant outlier class, and suggest classes where ADAMS may be retrained, if desired. Thus there is an important role for both classification techniques. Other mass spectral interpretation methods such as peak occurrence measurements, or more laboriously, individual spectra investigation, should continue to be completed in parallel to compliment ADAMS classification results. Certainly no single method of mass spectral summary has been shown to give a complete chemical description.

More recently, bipolar instruments have been developed to acquire both the positive and negative ions simultaneously from aerosol particles. ADAMS would be well suited to the classification of these bipolar results, although a suitable training dataset would first be required. Ultimately, the trained ADAMS technique can be utilized in an on-line fashion. This potential for on-line classification using ADAMS was successfully demonstrated during a recent month-long sampling campaign, and will be described in a future publication. 


\section{Conclusions}

A novel algorithm for discriminant analysis of mass spectra-ADAMS - was successfully developed. Validation tests on the mass spectra from standard chemicals showed that ADAMS classified these spectra into expected chemically-assigned classes. Tests on ADAMS with polystyrene latex particles doped with different salts revealed that ADAMS could be trained for preferential sensitivity to a given chemical marker. The application of ADAMS to both ambient PM and source PM yielded a common basis for comparison of receptor and source samples from aerosol LAMS.

\section{Acknowledgments}

Funding for this project was provided by a science subvention grant awarded by the Atmospheric Environment Service, by the Oil, Gas and Energy Branch of Environment Canada under contract K2340-9-0006, and by Health Canada under the Toxic Substances Research Initiative. The Natural Sciences and Engineering Research Council, the Canada Foundation for Innovation, and the Ontario Research and Development Challenge Fund supplied infrastructure funding. The authors give special thanks to Dr. Jeffrey R. Brook at the Meteorological Services of Canada for his continued support.

\section{References}

1. Johnston, M. V. Sampling and Analysis of Individual Particles by Aerosol Mass Spectrometry. J. Mass Spectrom. 2000, 35, 585-595.

2. Hinz, K-P.; Kaufmann, R.; Spengler, B. Simultaneous Detection of Positive and Negative Ions from Single Airborne Particles by Real-Time Laser Mass Spectrometry. Aerosol Sci. Technol. 1996, 24, 233-242.

3. Ro, C-U.; Musselman, I. H.; Linton, R. W. Molecular Speciation of Microparticles: Application of Pattern Recognition Techniques to Laser Microprobe Mass Spectrometric Data. Anal. Chim. Acta. 1991, 243, 139-147.

4. Xhoffer, C.; Bernard, P.; Van Grieken, R.; Van der Auwera, L. Chemical Characterization and Source Apportionment of Individual Aerosol Particles over the North Sea and the English Channel Using Multivariate Techniques. Environ. Sci. Technol. 1991, 25, 1470-1478.

5. Xhoffer, C.; Wouters, L.; Van Grieken, R. Characterization of Individual Particles in the North Sea Surface Microlayer and Underlying Seawater: Comparison with Atmospheric Particles. Environ. Sci. Technol. 1992, 26, 2151-2162.

6. Shattuck, T. W.; Germani, M. S.; Buseck, P. R. Multivariate Statistics for Large Data Sets: Applications to Individual Aerosol Particles. Anal. Chem. 1991, 63, 2646-2656.

7. Song, X. H.; Hopke, P. K.; Fergensen, D. P.; Prather, K. A. Classification of Single Particles Analyzed by ATOFMS Using an Artificial Neural Network, ART-2a. Anal. Chem. 1999, 71, 860-865.

8. Phares, D. J.; Rhoads, K. P.; Wexler, A. S.; Kane, D. B.; Johnston, M. V. Application of the ART-2a Algorithm to Laser Ablation Aerosol Mass Spectrometry of Particle Standards. Anal. Chem. 2001, 73, 2338-2344.

9. Thomson, D. S.; Murphy, D. M. Analyzing Single AerosolParticles in Real-Time-Composition Analysis of Aerosols is Critical to an Understanding of their Origins and Fate-This is done by Combining Time-of-Flight Mass Spectroscopy with
Optical-Particle Detections and Sizing. Chemtech. 1994, 24, 30-35.

10. Neubauer, K. R.; Sum, S. T.; Johnston, M. V.; Wexler, A. S. Sulfur Speciation in Individual Aerosol Particles. J. Geophys. Res. 1996, 101(D13), 18701-18707.

11. Reilly, P. T. A.; Lazar, A. C.; Gieray, R. A.; Whitten, W. B.; Ramsey, J. M. The Elucidation of Charge Transfer Induced Matrix Effects in Environmental Aerosols Via Real-Time Aerosol Mass Spectral Analysis of Individual Airborne Particles. Aerosol Sci. Technol. 2000, 33, 135-152.

12. Neubauer, K. R.; Johnston, M. V.; Wexler, A. S. Chromium Speciation in Aerosols by Rapid Single Particle Mass Spectrometry. Int. J. Mass Spectrom Ion Processes. 1995, 151, 77-87.

13. Harrington, P. B.; Street, T. E.; Voorhees, K. J.; Radicati di Brozolo, F.; Odom, R. W. Rule-Building Expert System for Classification of Mass Spectra. Anal. Chem. 1989, 61, 715-719.

14. Hinz, K-P.; Greweling, M.; Drews, F.; Spengler, B. Data Processing in On-line Laser Mass Spectrometry of Inorganic, Organic, or Biological Airborne Particles. J. Am. Soc. Mass Spectrom. 1999, 10, 648-660.

15. Prather, K. A.; Nordmeyer, T.; Salt, K. Real-Time Characterization of Individual Aerosol Particles Using Time-of-Flight Mass Spectrometry. Anal. Chem. 1994, 66, 1403-1407.

16. Gard, E.; Mayer, J. E.; Morrical, B. D.; Dienes, T.; Fergenson, D. P.; Prather, K. A. Real-Time Analysis of Individual Atmospheric Aerosol Particles: Design and Performance of a Portable ATOFMS. Anal. Chem. 1997, 69, 4083-4091.

17. Weiss, M.; Verheijen, P. J. T.; Marijnissen, J. C. M.; Scarlett, B. On the Performance of an On-Line Time-of-Flight Mass Spectrometer for Aerosols. J. Aerosol Sci. 1997, 28, 159-171.

18. Carson, P. G.; Neubauer, K. R.; Johnston, M. V.; Wexler, A. S. On-Line Chemical Analysis of Aerosols by Rapid SingleParticle Mass Spectrometry. J. Aerosol Sci. 1995, 26, 535-545.

19. Murphy, D. M.; Thomson, D. S. Laser Ionization Mass Spectroscopy of Single Aerosol Particles. Aerosol Sci. Technol. 1995, 22, 237-249.

20. Hinz, K-P.; Kaufmann, R.; Spengler, B. Laser-Induced Mass Analysis of Single Particles in the Airborne State. Anal. Chem. 1994, 66, 2071-2076.

21. Everitt, B. Cluster Analysis. Heinemann Educational Books: London, 1974, pp 7-24.

22. Brown, M. T.; Wicker, L. R. In Handbook of Applied Multivariate Statistics and Mathematical Modeling; Tinsley, H. E. A.; Brown, S. D., Eds.; Academic Press: San Diego, 2000; Chap VIII.

23. Huberty, C. J. Applied Discriminant Analysis. John Wiley \& Sons: New York, 1994, pp 37-172.

24. Klecka, W. R. Discriminant Analysis. Sage Publications: Beverly Hills, 1980, pp 7-64.

25. Noble, C. A.; Prather, K. A. Real-Time Measurement of Correlated Size and Composition Profiles of Individual Atmospheric Aerosol Particles. Environ. Sci. Technol. 1996, 30, 2667-2680.

26. Murphy, D. M.; Thomson, D. S. Chemical Composition of Single Aerosol Particles at Idaho Hill: Positive Ion Measurements. J. Geophys. Res. 1997, 102(D5), 6341-6352.

27. Murphy, D. M.; Thomson, D. S. Chemical Composition of Single Aerosol Particles at Idaho Hill: Negative Ion Measurements . J. Geophys. Res. 1997, 102(D5), 6353-6368.

28. Silva, P. J.; Prather, K. A. On-Line Characterization of Individual Particles from Automobile Emissions. Environ. Sci. Technol. 1997, 31, 3074-3080.

29. Silva, P. J.; Liu, D-Y.; Noble, C. A.; Prather, K. A. Size and Chemical Characterization of Individual Particles Resulting from Biomass Burning of Local Southern California Species. Environ. Sci. Technol. 1999, 33, 3068-3076.

30. Silva, P. J.; Carlin, R. A.; Prather, K. A. Single Particle Analysis of Suspended Soil Dust from Southern California. Atmos. Environ. 2000, 34, 1811-1820. 
31. Lee, S-H.; Middlebrook, A. M.; Murphy, D. M.; Thomson, D. S. Chemical Components of Single Particles Measured Using Particle Analysis by Laser Mass Spectrometry (PALMS) During the Atlanta SuperSite Experiment: Focus on Organic/ Sulfate, Lead, Soot, and Mineral Particles. To be published.

32. Silva, P. J.; Prather, K. A. Interpretation of Mass Spectra from Organic Compounds in Aerosol Time-of-Flight Mass Spectrometry. Anal. Chem. 2000, 72, 3553-3562.

33. Turpin, B. J.; Saxena, P.; Andrews, E. Measuring and Simulating Particulate Organics in the Atmosphere: Problems and Prospects. Atmos. Environ. 2000, 34, 2983-3013.

34. Gross, D. S.; Galli, M. E.; Silva, P. J.; Prather, K. A. Relative Sensitivity Factors for Alkali Metal and Ammonium Cations in Single-Particle Aerosol Time-of-Flight Mass Spectra. Anal. Chem. 2000, 72, 416-422.

35. Allen, J. O.; Fergenson, D. P.; Gard, E. E.; Hughes, L. S.; Morrical, B. D.; Kleeman, M. J.; Gross, D. S.; Galli, M. E.; Prather, K. A.; Cass, G. R. Particle Detection Efficiencies of
Aerosol Time of Flight Mass Spectrometers under Ambient Sampling Conditions. Environ. Sci. Technol. 2000, 34, 211-217.

36. Gross, D. S.; Galli, M. E.; Silva, P. J.; Wood, S. H.; Liu, D-Y.; Prather, K. A. Single Particle Characterization of Automobile and Diesel Truck Emissions in the Caldecott Tunnel. Aerosol Sci. Technol. 2000, 32, 152-163.

37. Hankin, S. M.; John, P. Laser Time-of-Flight Mass Analysis of PAHs on Single Diesel Particulates. Anal. Chem. 1999, 71, 1100-1104.

38. Tan, P. V.; Fila, M. S.; Evans, G. J.; Jervis, R. E. Aerosol Laser Ablation Mass Spectrometry of Suspended Powders from PM Sources and Its Implications to Receptor Modeling. Waste Manage. Assoc. 2002, 52, 27-40.

39. Bhave, P. V.; Fergenson, D. P.; Prather, K. A.; Cass, G. R. Source Apportionment of Fine Particulate Matter by Clustering Single-Particle Data: Tests of Receptor Model Accuracy. Environ. Sci. Technol. 2001, 35, 2060-2072. 